
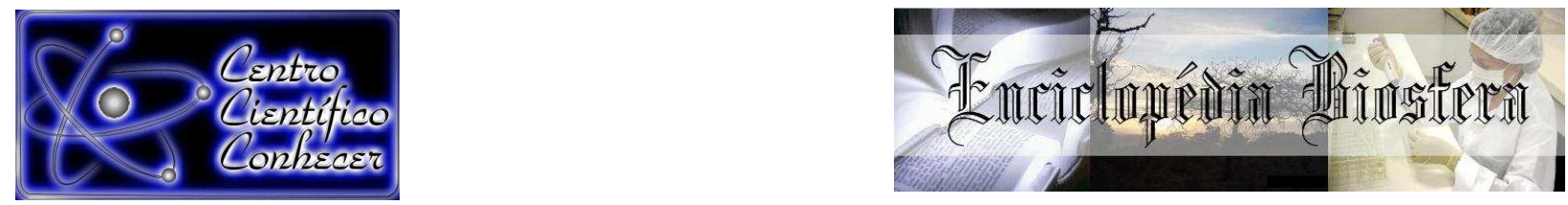

\title{
INTERVENÇÃO DOS TRATAMENTOS ESTÉTICOS NO PÓS-OPERATÓRIO DE GINECOMASTIA - RELATO DE CASO
}

Raquel Costa Machado1; Ana Paula Bordin Fernandes ${ }^{2}$; Carlos Fernandes Junior ${ }^{3}$; Ricardo de Melo Germano ${ }^{4}$

1Docente do curso de graduação em Estética e Cosmética da Universidade Paranaense, Campus-Paranavaí; Especialista em Estética avançada com ênfase em pré e pós-operatório em cirurgias plásticas.

${ }^{2}$ Docente do curso de graduação em Estética e Cosmética da Universidade Paranaense, Campus-Cianorte; Especialista em Estética avançada com ênfase em pré e pós-operatório em cirurgias plásticas.

${ }^{3}$ Médico cirurgião plástico, membro da Sociedade Brasileira de Cirurgia Plástica, Clinica Incorpore, Paranavaí.

${ }^{4}$ Docente do mestrado em Ciência Animal da Universidade Paranaense, CampusUmuarama-Sede. Umuarama, Paraná, Brasil. (germano@unipar.br)

Recebido em: 08/09/2015 - Aprovado em: 14/11/2015 - Publicado em: 01/12/2015 DOI: http://dx.doi.org/10.18677/Enciclopedia_Biosfera_2015_044

\begin{abstract}
RESUMO
A ginecomastia é uma cirurgia comum entre os homens, independente da idade. De origem multifatorial representa um aumento benigno da glândula mamária em indivíduos do sexo masculino, sendo as cirurgias indicadas quando o indivíduo apresenta alterações de sensibilidade ou dor local, bem como, quando os efeitos psicológicos e sociais atrapalham a rotina do indivíduo. Quando de longa duração, superior a 12 meses, não apresenta prognóstico de redução e muitas vezes evoluem para formação de uma massa densa e fibrose, sendo este indicativo cirúrgico. Os trabalhos têm relatado, para o pós-operatório, a drenagem linfática manual logo nos primeiros dias, auxiliando na redução do linfedema de membro superior, na diminuição do processo inflamatório, além de auxiliar na redução do quadro álgico. Baseado nesta premissa o objetivo deste relato de caso foi de realizar procedimentos estéticos no pós-cirúrgico de paciente de ginecomastia como coadjuvante na recuperação nesta etapa. O paciente foi submetido a 15 sessões de cuidado pós-operatório, utilizando a técnica de massagem drenagem linfático manual (DLM) associado ao aparelho de ultrassom. A massagem de DLM tem sido uma das técnicas mais utilizadas em procedimentos pós-operatórios, uma vez que seu objetivo principal é a diminuição do quadro de edema e com isto contribuindo de forma expressiva na recuperação tecidual. O indivíduo tratado apresentou melhora expressiva nas primeiras sessões realizadas. Conclui-se que, a aplicação da técnica de massagem de DLM, empregada no tecido lesado, possibilitou uma recuperação mais eficiente além de mais rápida, e que a associação do aparelho de ultrassom, também promove uma recuperação tecidual mais rápida, bem como a diminuição do quadro de fibrose instalada na região operada.
\end{abstract}

PALAVRAS-CHAVE: drenagem linfática manual, hipertrofia das glândulas mamárias, ultrassom. 


\title{
INTERVENTION IN THE AESTETIC POST OPERATIONAL TREATMENTS OF THE GYNECOMASTIA - CASE REPORT
}

\begin{abstract}
The gynecomastia is a common surgery among men despite their age. From a multifactorial origin it represents a benign growing of the mammary gland in male individuals, the surgery is approached when the person presents sensibility alterations and local pain as well as when the psychological and social effects disturb the individual's routine. When long lasting, more than 12 months, it doesn't show any prognostic of reduction and often develop to a dense mass formation and fibrosis which makes the individual suitable for the surgery. The researches has shown that the manual lymphatic drainage in the early days after surgery helps to reduce the arms lymphedema and the inflammation process in the post operational range, it also helps in the reduction of the pain symptoms. Based on these data the aim of this case description was to do aesthetics procedures in the gynecomastia patient as a supporting in this recuperation phase. The patient was submitted to 15 section of post operational care, using the manual lymphatic drainage (MLD) technique associated with an ultrasound machine. A MLD massage has been one of the most used techniques in the post operational process, once its main goal is the reduction of the edema contributing for expressive tissues recuperation. The patient treated presents a big improvement in the first sections. We conclude that the MLD massage technique, administrated in the injured tissue enabled a more efficient and faster recuperation which associated with the ultrasound machine also provides a faster tissues recuperation as well as a decreasing of the phibrosis in the operated region.
\end{abstract}

KEYWORDS: hypertrophy of the mammary glands, manual lynphatic drainage, ultrasound.

\section{INTRODUÇÃO}

A imagem pessoal é um fator importante no complexo mecanismo de identidade pessoal. A imagem que uma pessoa forma de si mesma, inter-relaciona através de três informações: a imagem idealizada ou a que se deseja ter, a representada pela impressão de terceiros e a objetiva ou a que a pessoa vê, através da percepção do seu próprio corpo. Dessa forma o aprimoramento da própria imagem ou sua manutenção, são motivações que levam o ser humano a realização de cirurgias plásticas e reparadoras (MELLO FILHO, 2010).

Os conceitos de beleza evoluíram ao longo da história da humanidade. Da mesma forma denota-se grande evolução na medicina estética, como o avanço de correções mais seguras e eficientes das alterações do contorno corporal não aceito pelo indivíduo, ou então pelos ditos, padrões sociais. Contudo, não somente no campo estético houve este avanço, mas também nas cirurgias corretivas, como no caso da ginecomastia que passaram a fazer parte das estatísticas das cirurgias plásticas no Brasil.

O aumento benigno da glândula mamária em indivíduos do sexo masculino é de origem multifatorial, sendo as cirurgias indicadas quando o indivíduo apresenta alterações de sensibilidade ou dor local, bem como, quando os efeitos psicológicos e sociais atrapalham a rotina do indivíduo. A ginecomastia de longa duração, superior a 12 meses, não apresenta prognóstico de redução, e muitas vezes, evolui para formação de uma massa densa e fibrosa. No pós-cirúrgico é recomendada a drenagem linfática manual já nos primeiros dias, auxiliando na redução do linfedema 
de membro superior, na diminuição o processo inflamatório e além de auxiliar na redução do quadro álgico.

Segundo a SOCIEDADE BRASILEIRA DE CIRURGIAS PLÁSTICAS (2014), a Ginecomastia é uma alteração comum entre os homens, independente da idade, podendo ser resultado de alterações hormonais, condições hereditárias, doenças ou utilização de certos medicamentos. A cirurgia em questão trata-se da redução de mama para homens, realizando a correção das glândulas mamárias demasiadamente desenvolvidas ou grandes.

A ginecomastia é conhecida desde o tempo de Aristóteles, mas foi Paulus Aegineta (625-690 d.C) quem fez a primeira referência ao tratamento cirúrgico, para qual se propôs incisão submamária, sendo utilizada até hoje por muitos cirurgiões (FRANCO, 2002). Caracteriza-se como um alargamento macio, simétrico e discoide da mama masculina. Pode ser definida como a proliferação benigna mais comum do tecido glandular da mama masculina, designa um aumento no tamanho da glândula mamária masculina, podendo ser fisiológico ou patológico (DORNELAS et al., 2010; MEDEIROS, 2012).

Clinicamente, se caracteriza por uma massa firme e elástica atrás e ao redor do complexo aréolo-mamilar e histologicamente, caracteriza-se pela proliferação de tecido adiposo, ductal e fibroso em diversas proporções (DORNELAS et al., 2010). Segundo RIBEIRO (2010) o aumento da glândula mamária pode ser palpável ou visível, uni ou bilateral presentes em adolescentes do sexo masculino, na faixa etária entre 13 e 15 anos, que pode ser fisiológica na puberdade, ou causada por patologias, medicamentos e genética.

A ginecomastia puberal fisiológica pode aparecer no período neonatal, pubertário ou senil, sendo que no período pubertário o aumento fisiológico da glândula mamaria masculina ocorre devido à hipertrofia do tecido conjuntivo e do sistema ductal, e o desequilíbrio dos hormônios andrógenos e estrógenos (RIBEIRO, 2010).

Com base na forma e no tamanho da mama, a ginecomastia pode ser classificada em quatro graus (Figura 1) (FRANCO, 2002), sendo:

Grau 1 - aumento pequeno, porém visível, do tecido mamário;

Grau 2A - aumento moderado do tecido mamário, sem redundância cutânea;

Grau 2B - aumento moderado do tecido mamário, com redundância cutânea;

Grau 3 - grande aumento do tecido mamário, com acentuada redundância cutânea; 


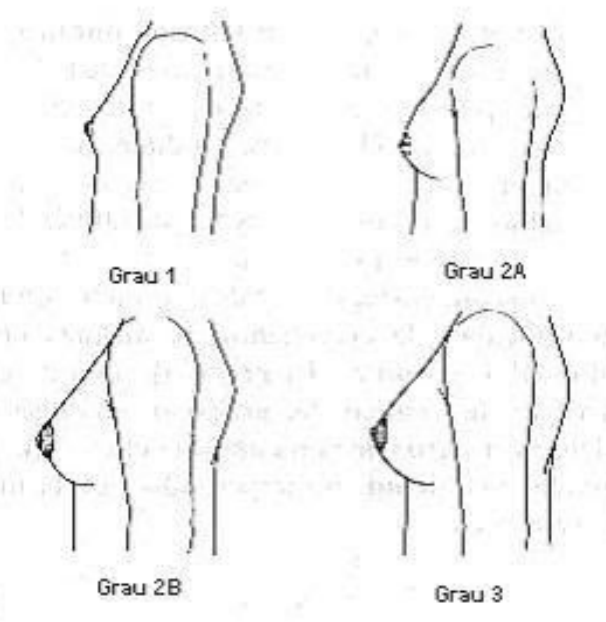

FIGURA 1: Diferentes graus de Ginecomastia - adaptado de SIMON et al. (1973)

Fonte: http://goo.gl//xMze6T

O tecido mamário origina-se embriologicamente do ectoderma, sendo um anexo da pele, e não exerce influência sobre as alterações ou desenvolvimento da musculatura peitoral. Anatomicamente, estão localizadas superiormente, entre a segunda e terceira costela, e inferiormente, entre a sétima e a oitava costela. Lateralmente, está localizada pela linha axilar anterior e medialmente, pela linha paraesternal (MAUAD JUNIOR, 2012).

O mamilo deve estar localizado na altura da quarta costela ou a dois a três centímetros abaixo da metade da altura do braço. O tecido mamário é sustentado por ligamentos, que se fixam ao músculo peitoral à pele, permitindo certo movimento da glândula mamária dentro do envelope de pele, servindo como suporte para a mama. A glândula mamária é composta de aproximadamente 20 lóbulos, que desembocam pelos ductos nos mamilos (MAUAD JUNIOR, 2012).

$\mathrm{Na}$ maioria dos casos de ginecomastia, o tratamento se dá mediante cirurgia plástica. $\mathrm{O}$ tratamento cirúrgico da ginecomastia apresenta grandes variações na literatura, o que reflete a ausência de protocolos amplamente aceitos, como tratamento por lipoaspiração devido ao resultado estético satisfatório e à menor incidência de complicações. Mas, a escolha da técnica cirúrgica deve ser baseada em características individuais de cada paciente (DORNELAS et al., 2010).

Além da escolha da técnica cirúrgica adequada a cada paciente (CARDOSO et al., 2007), torna-se necessária a realização de pós-operatório (P.O) visando à recuperação do paciente. As cirurgias plásticas reparadoras ou estéticas, na maioria, necessitam da utilização da técnica de massagem de drenagem linfática manual (DLM) no P.O, e deve ser iniciado o mais precocemente possível, devido à destruição dos vasos linfáticos causados pelo ato cirúrgico, causando dor, edema e diminuição da sensibilidade cutânea, gerando desconforto ao paciente. Quando realizada no P.O imediato promove melhora significativa no quadro álgico e desconforto, devido à diminuição da congestão tecidual, pelo auxilio na penetração do liquido excedente nos capilares sanguíneos e linfáticos intactos da região adjacente à lesão (RIBEIRO, 2004; BORGES, 2010). 
Baseado nesta premissa o objetivo deste relato de caso foi de realizar procedimentos estéticos no pós-cirúrgico de paciente de ginecomastia como coadjuvante na recuperação nesta etapa.

\section{RELATO DE CASO}

Esta pesquisa caracteriza-se em relato de caso, sendo avaliado um paciente do sexo masculino, com 14 anos de idade, tendo como fator de inclusão para esta pesquisa apresentar-se em período de P.O de cirurgia de ginecomastia, a qual foi constatada por meio de uma avaliação, acompanhada por questionário contendo: 1) Anamnese: identificação, dados pessoais, queixa principal; 2) Diagnóstico: levantamento do quadro clínico pós-operatório, como presença de edema, equimose, hematoma, dor, fibrose, complicação de cicatriz, entre outros.

\section{Relato médico}

Paciente V. L. S., 14 anos, solteiro, branco, com história de aumento mamário desde o início da puberdade, aumento gradativo que se estabilizou com volume semelhante a mamas femininas. Não foi relatado uso de medicamentos ou presença de patologias associadas. Foi devidamente examinado e diagnosticado como ginecomastia bilateral Grau 2B (SIMON et al., 1973). Após realização de exames pré-operatórios foi submetido a tratamento cirúrgico com retirada da glândula mamária associado à lipoaspiração, permanecendo com curativo por 24horas e dreno por três dias.

\section{Relato do caso}

Antes de iniciar o atendimento o paciente foi orientado quanto à realização do tratamento, bem como da anamnese e das sessões de tratamento. Após tomar conhecimento dos objetivos da pesquisa seu representante legal assinou o "Termo de Consentimento Livre e Esclarecido". Este estudo foi aprovado pelo Comitê de Ética em Pesquisa Envolvendo Seres Humanos (CEPEH) da Universidade Paranaense - UNIPAR, Certificado de Apresentação para Apreciação Ética (CAAE) número 33201414.8.0000.0109, e realizado no Centro de Estética Escola da UNIPAR, Campus de Paranavaí.

O paciente foi submetido a 15 sessões de cuidado pós-operatório, utilizando a técnica de massagem drenagem linfático manual (DLM) associada ao aparelho de ultrassom. Inicialmente, durante as dez primeiras sessões os atendimentos foram diários, com intervalo apenas no sábado e domingo e após esta primeira etapa foram realizadas três vezes por semana. O paciente foi orientado a não realizar movimentos que pudessem atrapalhar sua recuperação, como erguer os braços acima do ombro, expor-se ao sol durante o período de 30 dias após a cirurgia e utilizar a faixa compressiva durante 30 dias ou mais seguindo orientação médica.

Para a primeira sessão (quinto dia de P.O), foi realizada anamnese sendo relatado dor na região operada, e observado, por meio do exame palpatório fibrose acima das mamas direita e esquerda (próxima às axilas - região lipada). A sessão iniciou com aplicação do aparelho de ultrassom estético de $3 \mathrm{MHz}$, obedecendo aos seguintes parâmetros de calibragem: modo de emissão de onda pulsado, $16 \mathrm{~Hz}$ de frequência $20 \%$ de trabalho com potência de $0,4 \mathrm{~W} / \mathrm{cm}^{2}$, durante dois minutos na região axilar direita e esquerda após uso do ultrassom, realizou-se a DLM em toda região operada, respeitando o sentido da circulação linfática bem como as regiões ganglionares, sem movimentação do tecido, apenas toques leves e suaves com 
manobras de bombeamento parado e andando, após a sessão que durou 40 minutos o paciente relatou diminuição da dor, também foi possível observar melhora no quadro de edema e da fibrose, esta diminuição da fibrose pode estar associada à variação de temperatura local mesmo sendo muito discreta nesta calibragem. Esse protocolo foi mantido durante as 11 primeiras sessões havendo apenas variação na potência do ultrassom que ficou entre 0,4 a $0,8 \mathrm{~W} / \mathrm{cm}^{2}$, permanecendo o modo pulsado, frequência de $16 \mathrm{~Hz} 20 \%$ de trabalho, e tempo de dois minutos.

A partir da sexta sessão (completando 11 dias de P.O) foi introduzida a massagem em tecido conjuntivo para realinhamento das fibras e redução do tecido fibrosado, técnica de $S$ grande, na região de fibrose próxima a região axilar direita e esquerda, após aplicação de ultrassom, finalizando com a massagem de DLM. Completando esse primeiro ciclo o paciente não relatou dor, a fibrose apresentou diminuição pronunciada e o quadro de edema tornou-se gradualmente diminuído.

Após a $11^{\text {a }}$ sessão os parâmetros de calibragem do aparelho de ultrassom foram alterados para modo de emissão da onda contínuo e a potencia $0,8 \mathrm{~W} / \mathrm{cm}^{2}$, após aplicação do ultrassom foi realizada uma massagem mais vigorosa, técnica em $S$ grande, sobre a fibrose nas regiões citadas anteriormente, finalizando a sessão com a massagem de DLM. Esse protocolo foi realizado até a 15a sessão, com objetivo de diminuir a fibrose instalada nas regiões citadas anteriormente. Pode-se observar no período que compreende da $10^{\underline{a}}$ a $15^{\underline{a}}$ sessão que a fibrose instalada não existia mais e que o quadro de edema diminuiu satisfatoriamente.

Deve-se salientar que em todas as sessões a técnica da massagem de DLM realizada foi apenas de movimentos de bombeamentos parado e andando, realizados de proximal para distal, sem deslizamentos, com estimulação das regiões ganglionares próximas da região drenada.

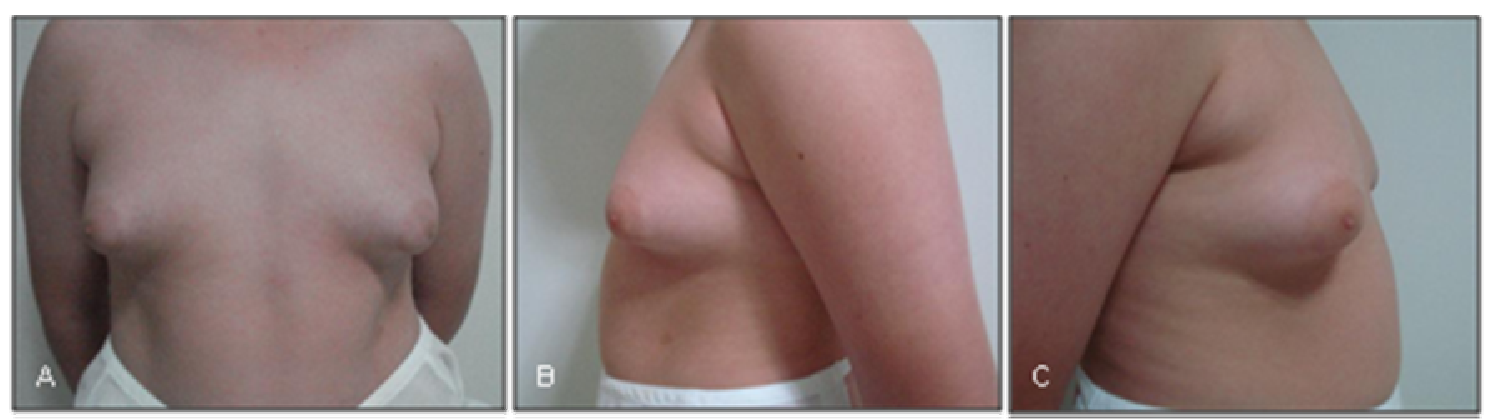

FIGURA 2: Paciente V.L.S. antes da cirurgia (A); mama esquerda antes da cirurgia (B); mama direita antes da cirurgia $(C)$

Fonte: arquivo pessoal.

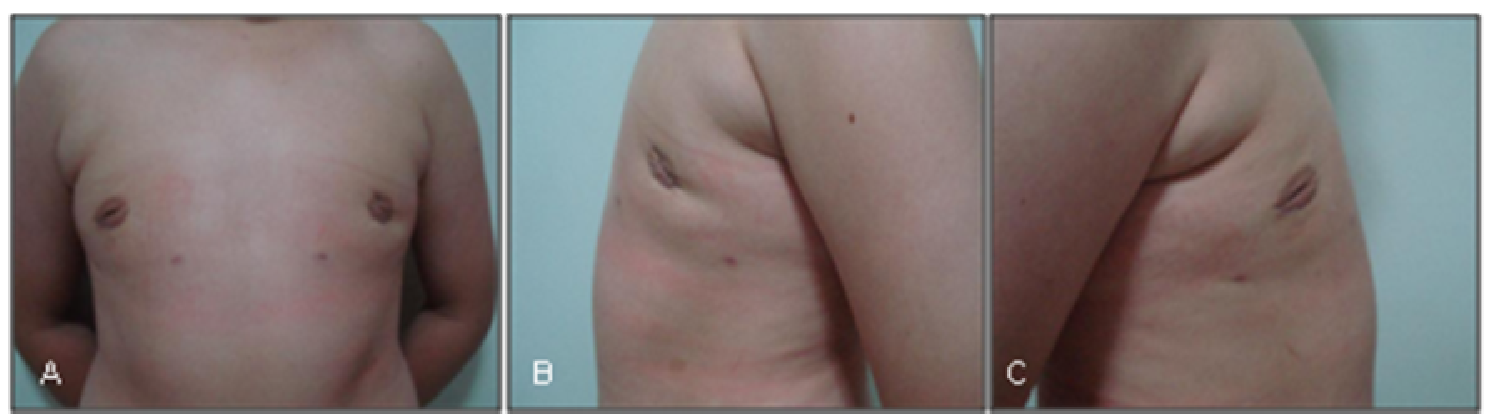

FIGURA 3: Paciente V.L.S. (A, B e C) 30 dias de P.O e na 15 a sessão de procedimentos estéticos

Fonte: arquivo pessoal. 


\section{RESULTADOS E DISCUSSÃO}

A massagem de DLM tem sido uma das técnicas mais utilizadas em procedimentos pós-operatórios, uma vez que o objetivo principal é diminuir o quadro de edema e com isto contribuir de forma expressiva na recuperação tecidual. Os procedimentos estéticos foram iniciados a partir do quinto dia de P.O, sendo este 0 primeiro dia útil após a retirada do curativo e dreno que se deu 24 horas após a cirurgia.

GUIRRO \& GUIRRO (2010) descrevem que a massagem de DLM pode ser iniciada entre 48 e 72 horas após a cirurgia, com movimentos rítmicos atuando de forma eficaz no linfedema proveniente do ato cirúrgico, e que movimentos deslizantes que acompanham diversas técnicas de drenagem são inadequados na fase aguda do reparo, podendo desenvolver tensões na lesão, aumentando a probabilidade de desenvolver uma cicatriz hipertrófica ou queloideana, além da sensibilidade desenvolvida na região operada.

Alguns parâmetros devem ser seguidos para a realização da DLM no P.O imediato, conforme LANGE (2012) menciona: executar as manobras do sentido proximal para distal e por um espaço de tempo maior nas regiões comprometidas. Essas manobras devem ser realizadas de forma lenta, pausada e repetitiva, respeitando o mecanismo fisiológico do transporte linfático que possui frequência de contração de cinco a sete vezes por minuto. Além disso, é importante exercer uma pressão manual que pode variar de 30 a 40 torr; não desencadear dor e que a duração mínima deve ser de 30 minutos. GUIRRO \& GUIRRO (2010) corroboram que a execução da massagem de DLM em P.O deve evitar os movimentos de deslizamento; deve-se seguir o trajeto das vias que não foram comprometidas através do ato cirúrgico; realizar os movimentos de modo suave evitando possíveis lesões teciduais.

Pode-se dizer que os parâmetros citados por LANGE (2012) e GUIRRO \& GUIRRO (2010) foram respeitados durante todas as sessões, comprovando que 0 trabalho realizado de forma proximal para distal, sentido da região glanglionar mais próxima da região lesada, com movimentos lentos e suaves, sem deslizamentos do retalho cutâneo, com pouca pressão, e com repetições maiores na região lesada, de fato traz benefícios ao tecido em recuperação e ao paciente no que diz respeito à dor, pois conforme a realização das manobras o paciente relatava alívio no quadro álgico, corroborando com que SCHWUCHOW et al. (2008) descreveram em estudo.

Segundo SOARES et al. (2005) há redução no edema pós-operatório após realização da massagem de DLM, reforçando a eficácia da referida massagem utilizada em P.O. LANGE (2012) descreve que as manobras de DLM são realizadas no P.O nas regiões edemaciadas, quando as comunicações linfáticas estão comprometidas e necessita-se encaminhar o líquido intersticial para uma região onde o sistema linfático superficial esteja íntegro para que possa ser absorvido.

Ainda durante a primeira sessão, em associação a DLM, foi iniciada a utilização do ultrassom com objetivo de reduzir a fibrose observada durante a avaliação, bem como promover a melhora no quadro álgico, na circulação sanguínea e linfática. Os parâmetros adotados na rotina seguiram os dados de GUIRRO \& GUIRRO (2010) com frequência pulsada na fase imediata a intervenção com intensidade, variando de 0,1 a $0,4 \mathrm{Wcm}^{2}$, sendo o tempo ajustado a cada nova sessão.

Ainda para os mesmos autores, no caso do processo de reparo ter sido concluído, havendo aderências e fibroses instaladas, a energia ultrassônica pode ser 
utilizada como coadjuvante na diminuição dessas sequelas, sendo, portanto indicada a utilização do ultrassom até o final do tratamento. Durante aplicação do ultrassom terapêutico com calibragem descrita anteriormente associada à aplicação da técnica de massagem de DLM, foi possível observar e sentir ao tato, a melhora do tecido lesado, alívio de dor relatado pelo paciente ao final de cada sessão, e a diminuição da fibrose já a partir da $10^{\underline{a}}$ sessão.

COUTINHO et al. (2006) reforçam que a massagem de DLM associada ao ultrassom terapêutico de $3 \mathrm{MHz}$ proporciona melhora no quadro de edema e dor, bem como favorecimento da reestruturação tecidual, acelerando o processo de reparo, melhorando a circulação veno-linfática e prevenção de possíveis complicações como seroma, aderência, entre outras relativas ao ato cirúrgico.

Vale destacar que na literatura consultada não há padronização das manobras realizadas na DLM, bem como consenso de uma única técnica a ser empregada e ainda de qual a melhor posição das mãos, sendo isto o indicativo da realização de novos trabalhos que possam ao testar diferentes técnicas contribuir para uma manobra mais eficiente no P.O.

\section{CONCLUSÃO}

A aplicação da técnica de massagem de DLM, empregada no tecido lesado, com pouca pressão, sem movimentação dos tecidos e logo no início do P.O possibilitou uma recuperação mais eficiente e mais rápida, nos quadros do póscirúrgico de ginecomastia. Também foi observado que a associação do aparelho de ultrassom, já a partir da primeira sessão, com os parâmetros adotados, promoveu uma recuperação mais rápida do tecido, bem como a diminuição do quadro de fibrose instalada na região operada.

Porém, sabe-se que o quadro de edema persiste em média de três a seis meses de P.O, tornando-se relevante a aplicação da técnica de massagem de DLM, pelo menos durante os três primeiros meses. Mesmo diante das respostas satisfatórias apresentadas neste estudo, são necessários mais estudos acerca da aplicação da técnica de massagem de drenagem linfática associada ao aparelho de ultrassom em pós-operatório de cirurgias plásticas.

\section{REFERÊNCIAS}

BORGES, F. S. Dermato-Funcional: modalidades terapêuticas nas disfunções estéticas. 2. ed. São Paulo: Phorte, 2010.

CARDOSO, A. A.; PAULINELLI, R. R.; FREITAS-JUNIOR, R.; RAHAL, R. M. S.; JACINTO, T. F. Análise comparativa da técnica da incisão em duplo círculo com as técnicas com incisão periareolar e transareolomamilar de correção cirúrgica da ginecomastia. Revista Brasileira de Ginecologia e Obstetricia. v. 29, n. 9, p. 465469, 2007.

COUTINHO, M. M.; DANTAS, R. B.; BORGES, A. S.; SILVA, I. C. A importância da atenção fisioterapêutica na minimização do edema nos casos de pós-operatório de abdominoplastia associada à lipoaspiração de flancos. Revista Fisioterapia Ser. n. 4, 2006. 
DORNELAS, M. T.; MACHADO, D. C.; GONÇALVES, A. L. C. P.; DORNELAS, M. C.; CORREA, M. P. D. Tratamento cirúrgico da ginecomastia: uma análise criteriosa. Revista Brasileira de Cirurgia Plástica. v. 25, n. 3, p. 470-473, 2010.

FRANCO, T. (Ed.). Princípios da cirurgia plástica. São Paulo: Atheneu, 2002.

GUIRRO, E.; GUIRRO, R. Fisioterapia dermato-funcional: fundamentos, recursos, patologias. 3. ed. rev. e ampl. Barueri: Manole, 2010.

LANGE, A. Drenagem linfática no pós-operatório das cirurgias plásticas. Curitiba: Vitória Gráfica e Editora, 2012.

MAUAD JUNIOR, R. J. (Org.) Estética e cirurgia plástica: tratamento no pré e pósoperatório. 4. ed. São Paulo: Editora Senac, 2012.

MEDEIROS, M. M. M. Abordagem cirúrgica para o tratamento da ginecomastia conforme sua classificação. Revista Brasileira de Cirurgia Plástica. v. 27, n. 2, p. 277-282, 2012.

MELLO FILHO, J. (Ed.). Psicossomática hoje. 2. ed. Porto Alegre: Artes Médicas; 2010.

RIBEIRO, D. Drenagem linfática manual corporal. 4. ed. São Paulo: Senac. 2004.

RIBEIRO, P. C. P. Alterações mamárias - diagnóstico clinico e diferencial. Revista Adolescência e Saúde. v. 7, n. 3, p. 27-32, 2010.

SCHWUCHOW, L.; SOUZA, V. P.; PELLINI, E.; CALOY, L. RESENDE, T. L. Estudo do uso da drenagem linfática manual no pós-operatório da lipoaspiração de tronco em mulheres. Revista da Graduação. v. 1, n. 1, p.1-9, 2008.

SIMON, B. E.; HOFFMAN, SAUL M.; KAHN, SIDNEY M. Classification and surgical correction of gynecomastia. Plastic \& Reconstructive Surgery, v. 51, n. 1, p. 48-52, 1973.

SOARES, L. M. A.; SOARES, S. M. B.; SOARES, A. K. A. Estudo comparativo da eficácia da drenagem linfática manual e mecânica no pós-operatório de dermolipectomia. Revista Brasileira em Promoção da Saúde, v. 18, n. 4, p. 199204, 2005.

SOCIEDADE BRASILEIRA DE CIRURGIA PLÁSTICA - SBCP. Cirurgias para homens. (2014). Disponível em: http://www2.cirurgiaplastica.org.br/cirurgias-eprocedimentos/mama/ginecomastia/ Acesso em: 25 set. 2014. 